\title{
Simple Maneuver to Tide over the Crisis due to Intraoperative Malfunctioning of a Pilot Balloon
}

\author{
Ankur Dhanda ${ }^{1}$ Surya Kumar Dube ${ }^{1}$ \\ ${ }^{1}$ Department of Neuroanaesthesiology and Critical Care, All India \\ Institute of Medical Sciences, New Delhi, India \\ ${ }^{2}$ Department of Neurosurgery, All India Institute of Medical \\ Sciences, New Delhi, India
}

J Neuroanaesthesiol Crit Care 2018;5:204-205
A 24-year-old male patient was posted for spinal instrumentation for listhesis of the first and second dorsal spine. He had a history of road traffic accident with associated cervical spine injury. Prior to surgery, the patient had an elective tracheostomy in view of anticipated prolonged mechanical ventilation. The patient underwent the surgery using a standard anesthetic technique of propofol, rocuronium, fentanyl, sevoflurane, oxygen, and air under recommended patient monitoring. After induction of anesthesia, invasive arterial monitoring was initiated and the patient was placed in prone position properly. The surgery went well for next 3 hours, and after that, we observed a ventilator alarm indicating inadequate tidal volume being delivered to the patient. We immediately started manually ventilating the patient's lungs with $100 \%$ oxygen and tried to figure out the source of gas leak. After a thorough investigation, we figured out the tracheostomy tube cuff leak to be the reason for the air leak in the circuit. We tried to inflate the cuff with air but failed to maintain the cuff inflation due to fault in the pilot balloon.

Because the surgery was at a crucial stage, it was not possible to make the patient supine. Hence, to tide over this airway crisis, we inflated the pilot balloon again and clamped the inflation tube with artery forceps. This maneuver contained the air leak only for a brief duration. Therefore, we again inflated the pilot balloon, clamped the inflation tube, and cut the inflation tube near the pilot balloon. A 22-gauge intravenous cannula was then carefully inserted inside the inflation tubing; the needle was removed and the sheath was left in situ; and then the artery forceps were removed. Thereafter, a three-way stopcock was attached to the cannula, tracheal cuff was inflated through the cannula, and the stopcock was closed to block the deflation of the cuff ( - Fig. 1). Mechanical ventilation was again resumed, and after observing the adequacy of oxygenation and ventilation for some time, the surgery was restarted. At any point of time, the patient had no episode of desaturation. Rest of the surgery went uneventful and the patient was made supine after the surgery. The tracheostomy tube was changed; then the neuromuscular blockade was reversed, and then the
Address for correspondence Surya Kumar Dube, MD, DM, Department of Neuroanaesthesiology and Critical Care, 7th Floor, Neurosciences Center, All India Institute of Medical Sciences, New Delhi 110029, India (e-mail: surya.dube@yahoo.co.in).

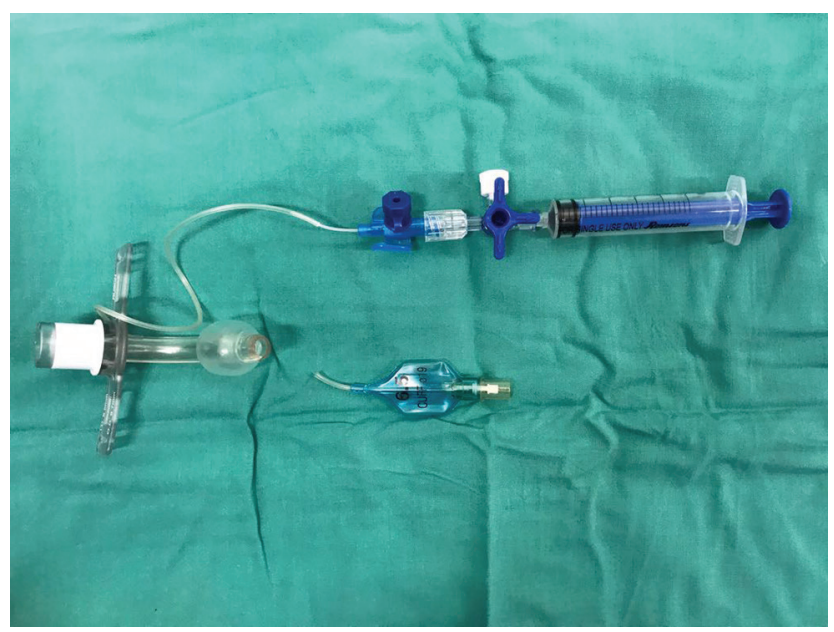

Fig. 1 Modified cuff inflation system.

patient was shifted to the neurosurgical intensive care unit (ICU) where he had a stable postoperative course.

Leak in a definitive airway device can cause problems such as minor air leak during mechanical ventilation or a life-threatening oxygenation/ventilator failure. It is advisable to replace a leaking definitive airway device, but many times it is not needed or safe to perform. Hence, replacement of a definitive airway device becomes essential when the conservative measures fail or there is an identifiable larger structural defect in the definitive airway device. ${ }^{1}$ In our case, we were able to maintain ventilation and oxygenation with certain maneuvers, and the surgical situation precluded shifting of the patient to supine position for the change of the leaking tracheostomy tube. Therefore, we did not change the tracheostomy tube. Maneuvers similar to ours are already described in the literature to manage cuff leak, where the authors introduced intravenous cannula into the inflation tube and attached a syringe directly to it and inflated the cuff., ${ }^{2,3}$ However, our method is slightly different from the others, as we removed the needle of the intravenous cannula keeping only the sheath inside the inflation tube, thereby allowing flexibility and eliminating the risk of accidental puncture of the inflation received

April 19, 2018

accepted after revision

June 5, 2018

published online

August 24, 2018
Dol https://doi.org/

10.1055/s-0038-1666883. ISSN 2348-0548.
Copyright $\odot 2018$ Indian Society of Neuroanaesthesiology and Critical Care
License terms

(ㄷ) (1) $\ominus \circledast$ 
tube by the needle. Second, we used a three-way stopcock to control accidental syringe disconnection-related air leak.

With this case report, we want to emphasize upon the fact that the method suggested by us may be useful in situations when there is a leak in the tracheostomy cuff due to failure of the inflation system and where there are genuine concerns for intraoperative changing of the tracheostomy tube. Also, in case of an accidental cutoff of the pilot balloon from the inflating channel, this technique can be used to inflate the cuff till the end of surgery, especially in prone position or in a patient with difficult airway. If the airway is away from the anesthesiologist, an arterial line extension can be connected to the cannula and the three-way stopcock can be closed for the anesthesiologist to monitor the cuff pressure and to inflate or deflate the cuff if necessary.

\section{Funding}

None.

\section{Conflict of Interest}

None.

\section{References}

1 El-Orbany M, Salem MR. Endotracheal tube cuff leaks: causes, consequences, and management. Anesth Analg 2013;117(2):428-434

2 Heusner JE, Viscomi CM. Endotracheal tube cuff failure due to valve damage. Anesth Analg 1991;72(2):270

3 Whitesides LM, Exler AS. Intraoperative damage and correction of pilot balloon during orthognathic surgery. Anesth Prog 1997;44(1):38-39 